\title{
EPR characterization of erbium in glasses and glass ceramics
}

\author{
Andris Antuzevics* \\ Institute of Solid State Physics, University of Latvia
}

* Corresponding author

E-mail: andris.antuzevics@cfi.lu.lv

\begin{abstract}
Electron paramagnetic resonance (EPR) is a well-established spectroscopic technique for electronic structure characterization of rare earth ion impurities in crystalline and amorphous hosts. EPR spectra of erbium doped glass matrices and nanocomposites can provide information about local structure variations induced by changes in chemical composition or crystallization processes. Characterization possibilities of $\mathrm{Er}^{3+}$ ions in glasses and glass ceramics including direct EPR measurements, indirect investigations via secondary paramagnetic probes and optically detected magnetic resonance techniques are considered in this article.
\end{abstract}

Keywords: electron paramagnetic resonance (EPR); erbium; oxyfluoride; glass; glass ceramics.

\section{Introduction}

Erbium incorporation into glass hosts is a major technological breakthrough in the development of fibre lasers and amplifiers, which has led to remarkable advances in optical fibre communications industry [1-4]. Additionally, the energy level arrangement of $\mathrm{Er}^{3+}$ is suitable for infrared radiation up-conversion into visible light, enabling erbium doped materials to be used as radiation visualisation screens and temperature sensors [5-8]. Transparent glass ceramics containing fluoride nanocrystals have been studied as promising hosts for $\mathrm{Er}^{3+}$ with up-conversion luminescence efficiency orders of magnitude higher in crystallized samples in comparison to precursor glasses [9-13]. Luminescence characteristics of a rare earth ion are inextricably linked with its local environment, a complete analysis of which requires a combination of several complementary spectroscopic techniques. This paper overviews the applicability of electron paramagnetic resonance (EPR) spectroscopy in the investigations of erbium doped glasses and glass ceramics.

Spectroscopic properties of rare earth ions are governed by the electrons of the $4 \mathrm{f}$ shell. The outer $5 \mathrm{~s}$ and $5 \mathrm{p}$ electron shells shield the $4 \mathrm{f}$ shell from the local environment, therefore energies of the $4 \mathrm{f}$ levels are well separated from each other and in the first approximation appear to be rather insensitive to the host matrix [14]. According to the Hund's rules, the ground state of $\mathrm{Er}^{3+} 4 \mathrm{f}^{11}$ electron configuration has an electron spin $S=3 / 2$ and an orbital angular momentum $L=6$, which gives the possible values of $J=15 / 2,13 / 2,11 / 2$ and $9 / 2$. The ${ }^{4} I_{15 / 2}$ level has the lowest energy because the $4 \mathrm{f}$ shell is more than halffilled. A schematic illustration of $\mathrm{Er}^{3+}$ energy level structure is given in Fig. 1; the energy values have 
been assigned according to Refs [15-17]. When incorporated in a crystal, $\mathrm{Er}^{3+}$ is subjected to electric fields exerted by surrounding atoms. The crystal field splits the degenerate $4 \mathrm{f}$ levels into a number of Stark components determined by the symmetry and strength of the field. $\mathrm{Er}^{3+}$ ground state can be split into either 5 Stark sublevels in cubic symmetry or 8 components in lower symmetry field [18]. In luminescence spectroscopy it appears as the fine structure of optical spectra and is a powerful tool for probing the structure of the host matrix [12-14]. The external magnetic field applied in conventional EPR experiments produces only a small perturbation of the lowest lying Kramer's doublet of the ${ }^{4} \mathbf{I}_{15 / 2}$ ground state in form of the Zeeman splitting.

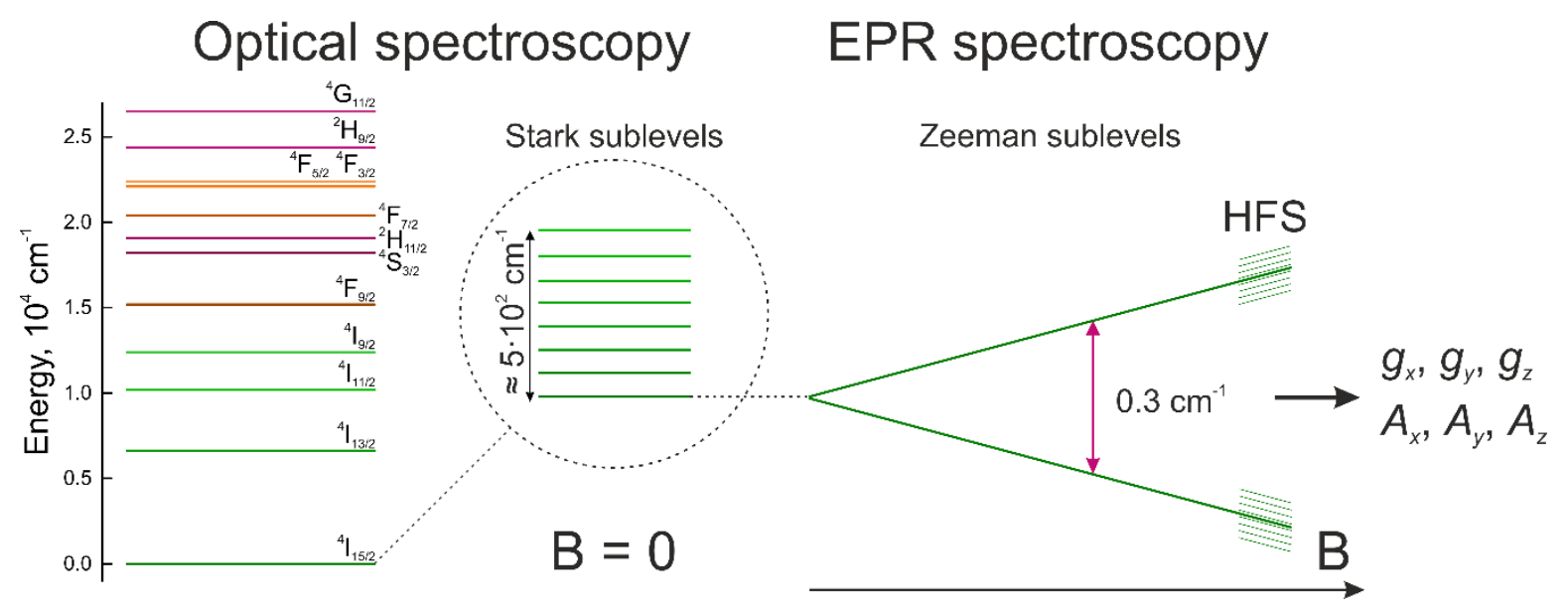

Fig. 1. An illustration of $\mathrm{Er}^{3+}$ energy levels.

Most rare earth ions are strongly coupled to lattice vibrations resulting in short spin-lattice relaxation times, which makes EPR spectra detection feasible at low temperature only [19]. Typical $\mathrm{Er}^{3+}$ signal detection range is $4-20 \mathrm{~K}$ [20]; above $30 \mathrm{~K}$ spectra are usually unobservable [21-23], however, there are cases, when for selected orientations erbium resonances can be observed up to $80 \mathrm{~K}$ [19].

\section{Experimental details}

Oxyfluoride samples synthesized by the melt quenching technique of the following compositions have been investigated: $19 \mathrm{NaO}_{2}-7 \mathrm{BaF}_{2}-7 \mathrm{YF}_{3}-6 \mathrm{Al}_{2} \mathrm{O}_{3}-60 \mathrm{SiO}_{2}-1 \mathrm{ErF}_{3}(\mathrm{BYF}), 19 \mathrm{NaO}_{2}-7 \mathrm{NaF}-7 \mathrm{YF}_{3}-6 \mathrm{Al}_{2} \mathrm{O}_{3}-$ $60 \mathrm{SiO}_{2}-1 \mathrm{ErF}_{3}$ (NYF) [11] and $8 \mathrm{CaCO}_{3}-25.4 \mathrm{CaF}_{2}-20.5 \mathrm{Al}_{2} \mathrm{O}_{3}-46 \mathrm{SiO}_{2}-0.1 \mathrm{Er}_{2} \mathrm{O}_{3}$ (CF) [24]. CF glass ceramics have been obtained by an isothermal heat treatment at $700{ }^{\circ} \mathrm{C}$ for $1 \mathrm{~h}$.

EPR spectra were measured at $10 \mathrm{~K}$ with Bruker ELEXSYS-II E500 CW-EPR spectrometer equipped with a liquid helium flow cryostat. Magnetic field modulation parameters were $100 \mathrm{kHz}$ and $0.1 \mathrm{mT}$; microwaves were generated at $9.36 \mathrm{GHz}$ frequency and $0.6325 \mathrm{~mW}$ power. EPR spectra simulations have been performed in Easyspin toolbox [25] for Matlab. 


\section{Results and discussion}

\subsection{Direct EPR detection}

Microwave quanta generated in conventional X-band EPR experiments probe only the lowest lying sublevel of the ${ }^{4} \mathrm{I}_{15 / 2}$ manifold of trivalent erbium. Consequently, a simple effective spin $S=1 / 2$ system can be used to account for the features of $\mathrm{Er}^{3+} \mathrm{EPR}$ spectra:

$$
H=\mu_{B} B g S+S A I
$$

where the Zeeman term represents energy of the spin in magnetic field $B$ and the second term - the hyperfine interaction energy with nuclear spins $I \neq 0 . \mu_{B}$ is the Bohr magneton and $g$ and $A$ are interaction tensors, which reflect local structure peculiarities of the paramagnetic complex. Hyperfine structure (HFS) in $\mathrm{Er}^{3+}$ spectra arises from $S$ interaction with the $23 \%$ abundant ${ }^{167} \mathrm{Er}$ isotope with $I=7 / 2$. This produces an approximatelly symetrical HFS pattern of 8 components with $3.7 \%$ amplitude of the central line [18]. Typical Er ${ }^{3+}$ EPR spectra are presented in Fig. 2; the curves have been obtained from simulations with parameters reported for the cubic $\mathrm{CaF}_{2}: \mathrm{Er}^{3+}$ center [26,27].

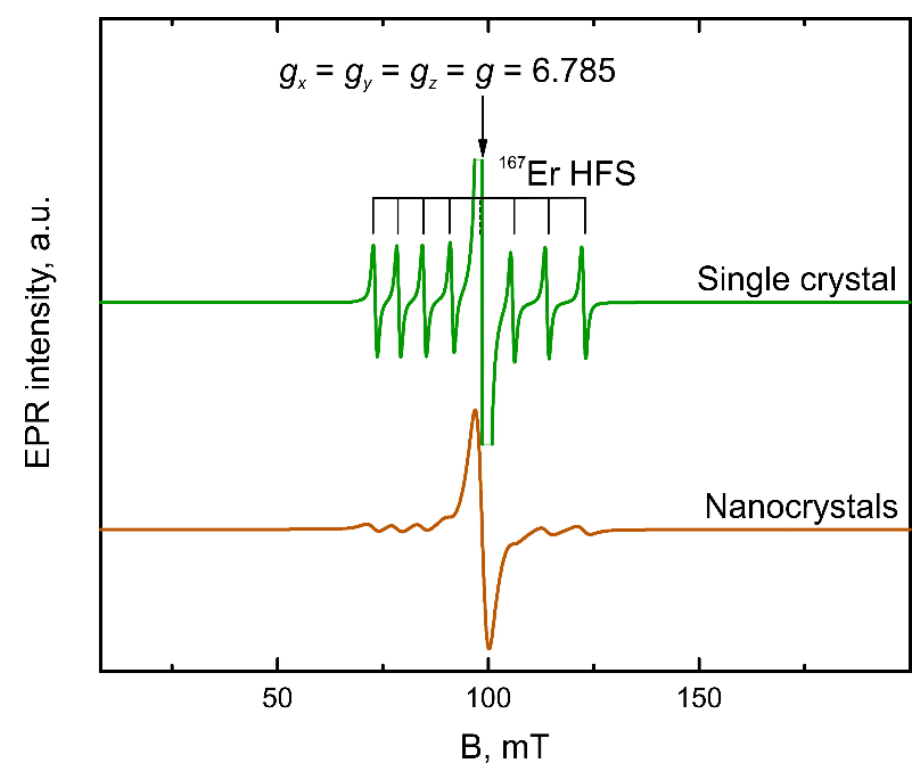

Fig. 2. EPR spectra simulations of the cubic $\mathrm{CaF}_{2}: \mathrm{Er}^{3+}$ centre.

$\mathrm{Er}^{3+} \mathrm{EPR}$ spectra are isotropic in a cubic environment. The high symmetry crystal field decomposes the sixteen-fold degeneracy of the ${ }^{4} \mathrm{I}_{15 / 2}$ level into three quartets $\Gamma_{8}$ and two doublets $\Gamma_{6}$ and $\Gamma_{7}$. The determined value of $g$ can serve as the "fingerprint" in assigning the lowest-lying level [18]. In lower symmetry $\mathrm{Er}^{3+}$ complexes splitting into a maximum of eight Kramer's doublets can occur. In general, analysis of angle-dependent behaviour of resonance positions in single crystals is necessary for a determination of principal components of $g$ and $A$ tensors. For the case of lower symmetry $\mathrm{Er}^{3+}$ sites, 
spectra are highly anisotropic [18,21,28-30]. In policrystalline systems all crystal orientations are statistically equally probable. As a result, powder EPR spectrum reflects a superposition of all single crystal orientations [31]. In the case of non-cubic $\mathrm{Er}^{3+}$ centers it leads to orientation disorder induced EPR line broadening. If the particles are sufficiently small, structure disorder effects may also produce broadening in the spectral features, which has been demonstrated in $\mathrm{CaF}_{2}: \mathrm{Er}^{3+}[32]$ and $\mathrm{CeO}_{2}: \mathrm{Er}^{3+}[33]$ nanocrystalline systems. A tentative simulation of the effect is given as the second curve in Fig. 2. Note that for an equal number of spins the double integral of the EPR spectrum is conserved, thus the wider curve has a much smaller signal amplitude. In glasses structure disorder effects are more pronounced site-to-site variations in the local environment produce wide distributions in SH parameter values and, as a rule, broad spectral features are expected. Experimental EPR spectra of erbium doped oxyfluoride glasses are shown in Fig. 3 .

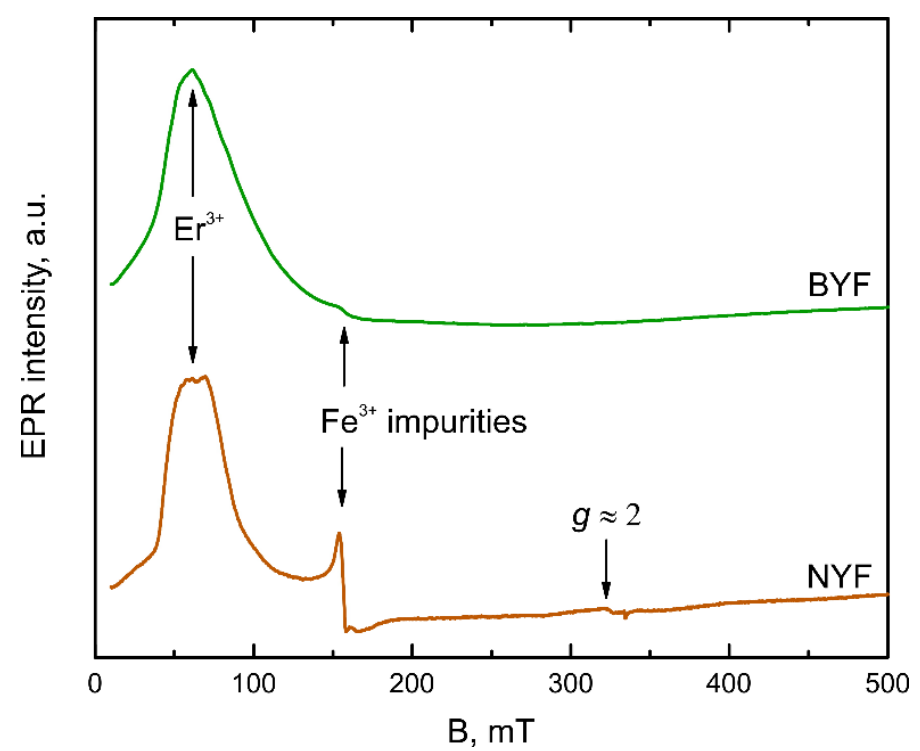

Fig. 3. EPR spectra of erbium doped oxyfluoride glasses.

An overlap of signals from diferent paramagnetic centres is resolved in the EPR spectra of glasses. $\mathrm{Fe}^{3+}$ impurities typically produce a resonance at $g=4.3(155 \mathrm{mT})[34,35]$, whereas signals related to glass network defects are expected in the vicinity of $g=2[35,36]$. The broad features at low field values are related to $\mathrm{Er}^{3+}$ ions residing in the glass matrix. Depending on the composition of the glass $\mathrm{Er}^{3+} g$ values in 6-10 range have been reported in literature [37-42]. Spectra feature assignment to erbium is usually based on the low temperature requirement for the detection of the signal. Alternatively, evidence for EPR signal association with $\mathrm{Er}^{3+}$ can be obtained from sample investigations with different levels of $\mathrm{Er}$ content [40,42]. For high levels of Er doping formation of Er-Er ion pairs can be expected, however literature data for the $g$ values of such features are not unambiguous $[41,42]$.

From a structural point of view glass ceramics can be considered as composite materials, where nanocrystalline structures are embedded within an amorphous matrix. This results in spectral patterns 
of signals associated with crystallites superimposing broader curves related to defects in glass $[43,44]$. In the studies of erbium doped glass ceramics EPR signal intensity or shape variations may occur indicating structural changes around the rare earth ion upon crystallization [39]. A comparison of EPR spectra double integral with a reference sample can provide quantitative information about erbium content in the crystalline phase [45]. In the case of complete ion segregation in the crystalline phase during the devitrification process, the broad $\mathrm{Er}^{3+}$ glass EPR signal can vanish completely, which has been demonstrated in glass ceramics containing $\beta-\mathrm{PbF}_{2}$ nanocrystals [38]. The reported EPR spectrum in glass ceramics (which is essentially the same as the bottom curve of Fig. 2 here) could be simulated with $\mathrm{SH}$ parameters determined in single crystal $\beta-\mathrm{PbF}_{2}$ providing evidence that same type of cubic symmetry $\mathrm{Er}^{3+}$ centres are created in single crystals as well as in glass ceramics [38].

An EPR spectrum of erbium doped oxyfluoride glass ceramics containing $\mathrm{CaF}_{2}$ crystalline phase is shown in Fig. 4. The determined $g$ value of the additional signal coincides with the simulations in Fig. 2 providing experimental evidence that $\mathrm{Er}^{3+}$ ions incorporate in the $\mathrm{CaF}_{2}$ nanocrystals in cubic site symmetry. The spectrum is too broad to resolve the HFS, which could be associated either with structural disorder effects or relatively high level of substitution of $\mathrm{Er}^{3+}$ within the nanocrystals.

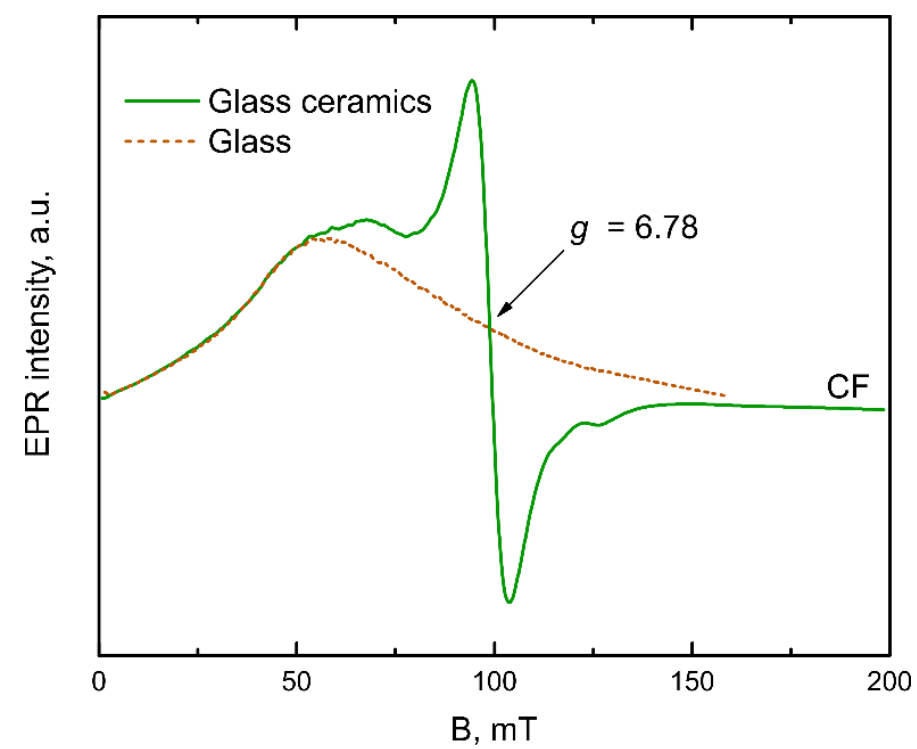

Fig. 4. EPR spectra of erbium doped oxyfluoride glass and glass ceramics samples.

\subsection{Indirect EPR detection}

A direct detection of $\mathrm{Er}^{3+} \mathrm{EPR}$ is problematic due to the requirement of low temperature and the fact that the energy of microwave quanta probes only the lowest lying Kramer's doublet of the ${ }^{4} \mathrm{I}_{15 / 2}$ manifold. As a consequence of the latter, EPR spectra of $\mathrm{Er}^{3+}$ are not always informative, e.g. in similar symmetry hosts, where only slight variations in the $g$ values could be expected. 
An alternative approach is the introduction of paramagnetic probes, for which EPR spectra features are sensitive to local structure variations induced by the primary dopant. This principle has been demonstrated in $\mathrm{CaF}_{2}$-containing oxyfluoride glass ceramics co-doped with $\mathrm{Gd}^{3+}$ and $\mathrm{Eu}^{3+}[46]$. $\mathrm{Gd}^{3+}$ is an excellent EPR probe, which exhibits a strong signal detectable at room temperature, while the fine structure features of the spectrum are host-sensitive [47]. $\mathrm{Eu}^{3+}$, on the other hand, is "EPR-silent" and does not contribute to EPR signal intensity [48]. $\mathrm{Gd}^{3+}$ EPR spectra dependence on the amount of $\mathrm{Eu}^{3+}$ doping in oxyfluoride glass ceramics is presented in Fig. 5.

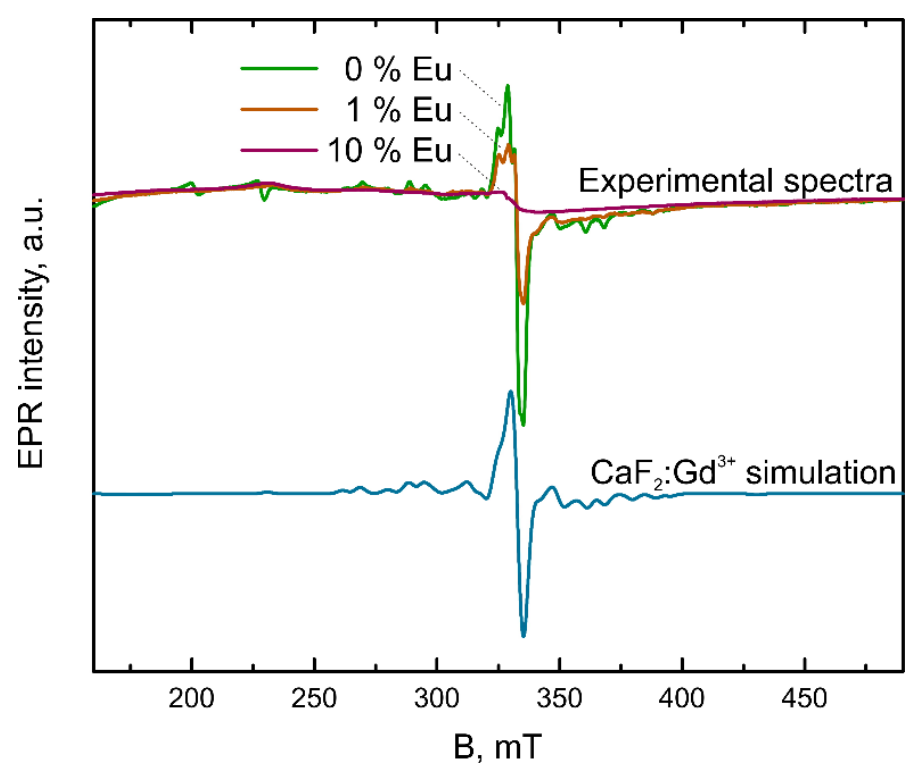

Fig. 5. Room temperature EPR spectra of gadolinium/europium co-doped glass ceramics containing $\mathrm{CaF}_{2}$ nanocrystals [46]. Simulation curve represents the expected curve for cubic $\mathrm{CaF}_{2}: \mathrm{Gd}^{3+}$ centres.

The EPR spectrum of the sample singly doped with $\mathrm{Gd}^{3+}$ can be simulated with SH parameters reported for the cubic $\mathrm{CaF}_{2}: \mathrm{Gd}^{3+}$ centre [20]. With the introduction of second rare-earth ion in the matrix EPR spectra associated with the cubic $\mathrm{Gd}^{3+}$ centre are broadened. It indicates that $\mathrm{Eu}^{3+}$ ions also incorporate the $\mathrm{CaF}_{2}$ phase of glass ceramics and distort the cubic local environment around $\mathrm{Gd}^{3+}$ sites. It has been shown, that for a low-to-medium Eu-doping range variations in $\mathrm{Gd}^{3+} \mathrm{EPR}$ spectra can be used for a quantitative analysis of the rare earth ion incorporation efficiency in the crystalline phase of glass ceramics [46]. Structural changes detected via $\mathrm{Gd}^{3+}$ probe spectra have been also demonstrated for other rare earth ions, e.g. $\mathrm{Ce}^{3+}, \mathrm{La}^{3+}, \mathrm{Y}^{3+}[49-51]$, thus it could be a feasible strategy in the studies of systems containing erbium.

\subsection{Optical detection of EPR}

A direct correlation of optical properties to particular defect or impurity centres can be achieved via optically detected magnetic resonance (ODMR) measurement techniques. One of the variations of 
ODMR is EPR detected via magnetic circular dichroism (MCD-EPR) [52]. MCD and MCD-EPR spectra for erbium doped CF glass ceramics are shown in Fig. 6 [24].

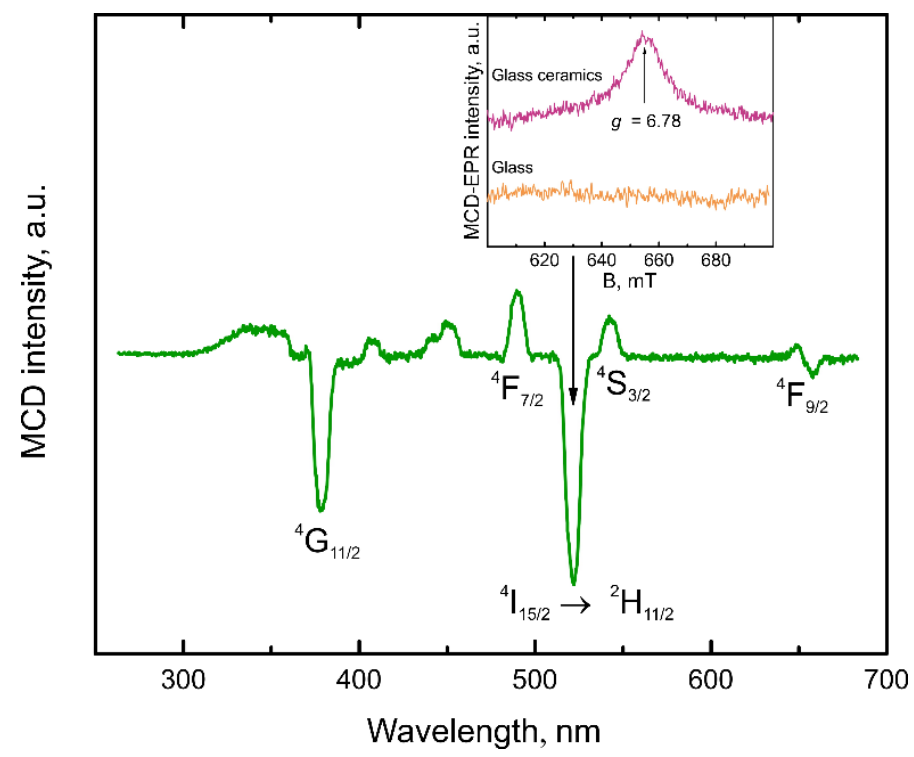

Fig. 6. $\mathrm{MCD}$ spectrum of erbium doped oxyfluoride glass ceramics containing $\mathrm{CaF}_{2}$ nanocrystals detected at $1.5 \mathrm{~K}$ and $1 \mathrm{~T}$. Inset shows $62 \mathrm{GHz}$ MCD-EPR spectra of the glass ceramics and respective glass samples measured at $521 \mathrm{~nm}$ MCD band [24].

In MCD-EPR detection, first, an MCD spectrum of a sample is obtained. The features of the MCD spectrum should correlate with the optical absorption spectrum as the same transitions are induced. Afterwards, variable temperature MCD measurements are carried out to determine, which of the bands possess paramagnetic behaviour. In this case MCD intensity should be inversely proportional to temperature. If paramagnetic behaviour is detected, the excitation wavelength can be fixed and an MCDEPR experiment is carried out by sweeping magnetic field at a fixed microwave frequency. When the EPR resonance condition is met, changes in the MCD intensity occur and are detected [53].

In the inset of Fig. 6 an MCD-EPR signal at $g=6.78$ is resolved in CF glass ceramics, which is not present in the precursor glass. The $g$ value suggests that it is caused by $\mathrm{Er}^{3+}$ ions in $\mathrm{CaF}_{2}$ in cubic site symmetry (see Fig. 2 and Fig. 4). It can be concluded that a part of $\mathrm{Er}^{3+}$ ions incorporate the crystalline phase of glass ceramics and contribute to the ${ }^{4} \mathrm{I}_{15 / 2} \rightarrow{ }^{2} \mathrm{H}_{11 / 2}$ MCD transition [24].

\section{Conclusions}

Direct EPR investigations of erbium-doped materials require low temperature and provide information about the Zeeman splitting and hyperfine interactions of the ground state. The interaction parameters are host dependent, which enable unique characterization possibilities of $\mathrm{Er}^{3+}$ ions in glasses and glass ceramics. ODMR techniques can be applied, when a direct correlation with optical spectra needs to be 
established. Alternatively, secondary paramagnetic probe ions can be introduced in the matrix to characterize the local environment of the primary rare earth ion.

\section{Acknowledgements.}

The author expresses gratitude to Guna Krieke and prof. Uldis Rogulis for valuable discussions during the preparation of this article. This research is funded by the Latvian Council of Science, project "Novel transparent nanocomposite oxyfluoride materials for optical applications", project No. LZP-2018/10335 .

\section{References}

[1] L. Reekie, R.J. Mears, S.B. Poole, D.N. Payne, Tunable Single-Mode Fiber Lasers, J. Light. Technol. 4 (1986) 956-960. doi:10.1109/JLT.1986.1074827.

[2] R.J. Mears, L. Reekie, S.B. Poole, D.N. Payne, Low-threshold tunable CW and Q-switched fibre laser operating at $1.55 \mu \mathrm{m}$, Electron. Lett. 25 (1989) 58-59.

[3] E. Desurvire, J.R. Simpson, P.C. Becker, High-gain erbium-doped traveling-wave fiber amplifier, Opt. Lett. 12 (1987) 888. doi:10.1364/ol.12.000888.

[4] P. Urquhart, Review of rare earth doped fibre lasers and amplifiers, IEE Proc. J. 135 (1988) 385407. https://digital-library.theiet.org/content/journals/10.1049/ip-j.1988.0071.

[5] T. Sun, Z.Y. Zhang, K.T.V. Grattan, Erbium/ytterbium fluorescence based fiber optic temperature sensor system, Rev. Sci. Instrum. 71 (2000) 4017-4022. doi:10.1063/1.1289682.

[6] J. Castrellon, G. Paez, M. Strojnik, Remote temperature sensor employing erbium-doped silica fiber, Infrared Phys. Technol. 43 (2002) 219-222. doi:10.1016/S1350-4495(02)00142-1.

[7] F. Vetrone, R. Naccache, A. Zamarrón, A.J. De La Fuente, F. Sanz-Rodríguez, L.M. Maestro, E.M. Rodriguez, D. Jaque, J.G. Sole, J.A. Capobianco, Temperature sensing using fluorescent nanothermometers, ACS Nano. 4 (2010) 3254-3258. doi:10.1021/nn100244a.

[8] H. Yao, H. Shen, Q. Tang, J. Peng, R. Liu, Temperature-dependence of efficient up-conversion luminescence in $\mathrm{NaY}\left(\mathrm{WO}_{4}\right)_{2}$ nanophosphor doped with $\mathrm{Er}^{3+}$ for cryogenic temperature sensor, Mater. Chem. Phys. 219 (2018) 361-367. doi:10.1016/j.matchemphys.2018.08.065.

[9] S. Tanabe, H. Hayashi, T. Hanada, N. Onodera, Fluorescence properties of $\mathrm{Er}^{3+}$ ions in glass ceramics containing $\mathrm{LaF}_{3}$ nanocrystals, Opt. Mater. (Amst). 19 (2002) 343-349. doi:10.1016/S0925-3467(01)00236-1.

[10] A. Sarakovskis, G. Krieke, Upconversion luminescence in erbium doped transparent oxyfluoride glass ceramics containing hexagonal $\mathrm{NaYF}_{4}$ nanocrystals, J. Eur. Ceram. Soc. 35 (2015) 36653671. doi:10.1016/j.jeurceramsoc.2015.06.014. 
[11] G. Krieke, A. Sarakovskis, Crystallization and upconversion luminescence of distorted fluorite nanocrystals in $\mathrm{Ba}^{2+}$ containing oxyfluoride glass ceramics, J. Eur. Ceram. Soc. 36 (2015) 17151722. doi:10.1016/j.jeurceramsoc.2016.01.025.

[12] G. Krieke, A. Sarakovskis, R. Ignatans, J. Gabrusenoks, Phase transitions and upconversion luminescence in oxyfluoride glass ceramics containing $\mathrm{Ba}_{4} \mathrm{Gd}_{3} \mathrm{~F}_{17}$ nanocrystals, J. Eur. Ceram. Soc. 37 (2017) 1713-1722. doi:10.1016/j.jeurceramsoc.2016.12.023.

[13] G. Krieke, A. Sarakovskis, M. Springis, Cubic and rhombohedral $\mathrm{Ba}_{4} \mathrm{Lu}_{3} \mathrm{~F}_{17}: \mathrm{Er}^{3+}$ in transparent glass ceramics: Crystallization and upconversion luminescence, J. Lumin. 200 (2018) 265-273. doi:10.1016/j.jlumin.2018.04.016.

[14] A. Polman, Erbium as a probe of everything?, Phys. B Condens. Matter. 300 (2001) 78-90. doi:10.1016/S0921-4526(01)00573-7.

[15] P. Kisliuk, W.F. Krupke, J.B. Gruber, Spectrum of $\mathrm{Er}^{3+}$ in single crystals of $\mathrm{Y}_{2} \mathrm{O}_{3}$, J. Chem. Phys. 40 (1964) 3606-3610. doi:10.1063/1.1725060.

[16] R.T. Wegh, E. V.D. Van Loef, G.W. Burdick, A. Meijerink, Luminescence spectroscopy of highenergy $4 \mathrm{f}^{11}$ levels of $\mathrm{Er}^{3+}$ in fluorides, Mol. Phys. 101 (2003) 1047-1056. doi:10.1080/0026897021000046906.

[17] X. Chen, E. Ma, G. Liu, Energy levels and optical spectroscopy of $\mathrm{Er}^{3+}$ in $\mathrm{Gd}_{2} \mathrm{O}_{3}$ nanocrystals, J. Phys. Chem. C. 111 (2007) 10404-10411. doi:10.1021/jp072980g.

[18] C.A.J. Ammerlaan, I. Maat-Gersdorf, Zeeman splitting factor of the $\mathrm{Er}^{3+}$ ion in a crystal field, Appl. Magn. $\quad$ Reson. $21 \quad$ (2001) 13-33. http://www.springerlink.com/index/10.1007/BF03162436\%5Cnpapers2://publication/doi/10.10 07/BF03162436.

[19] A.D. Prokhorov, A.A. Prokhorov, L.F. Chernysh, P. Aleshkevich, V. Dyakonov, H. Szymczak, EPR of $\mathrm{Nd}^{3+}$ and $\mathrm{Er}^{3+}$ ions in aluminum borates $\mathrm{YAl}_{3}\left(\mathrm{BO}_{3}\right)_{4}$ and $\mathrm{EuAl}_{3}\left(\mathrm{BO}_{3}\right)_{4}$, J. Magn. Magn. Mater. 326 (2013) 162-165. doi:10.1016/j.jmmm.2012.07.049.

[20] S.A. Al'tshulter, B.M. Kozyrev, Electron Paramagnetic Resonance in Compounds of Transition Elements, Wiley, 1974.

[21] P.G. Baranov, I. V. Ilyin, E.N. Mokhov, Electron paramagnetic resonance of erbium in bulk silicon carbide crystals, Solid State Commun. 103 (1997) 291-295. doi:10.1016/S00381098(97)00161-0.

[22] M.T. Borowiec, A.A. Prochorov, A.D. Prochorov, V.P. Dyakonov, H. Szymczak, Electron paramagnetic resonance spectra of $\mathrm{Er}^{3+}$ in the monoclinic $\mathrm{KY}\left(\mathrm{WO}_{4}\right)_{2}$ crystal, J. Phys. Condens. Matter. 15 (2003) 5113-5120. doi:10.1088/0953-8984/15/29/323.

[23] S. Yang, S.M. Evans, L.E. Halliburton, G.A. Slack, S.B. Schujman, K.E. Morgan, R.T. Bondokov, S.G. Mueller, Electron paramagnetic resonance of $\mathrm{Er}^{3+}$ ions in aluminum nitride, J. Appl. Phys. 105 (2009). doi:10.1063/1.3065532.

[24] U. Rogulis, A. Fedotovs, A. Antuzevics, D. Berzins, Y. Zhydachevskyy, D. Sugak, Optical 
detection of paramagnetic centres in activated oxyfluoride glass-ceramics, Acta Phys. Pol. A. 133 (2018) 785-788. doi:10.12693/APhysPolA.133.785.

[25] S. Stoll, A. Schweiger, EasySpin, a comprehensive software package for spectral simulation and analysis in EPR, J. Magn. Reson. 178 (2006) 42-55.

[26] U. Ranon, W. Low, Electron Spin Resonance of $\mathrm{Er}^{3+}$ in $\mathrm{CaF}_{2}$, Phys. Rev. 132 (1963) 1609-1611. doi:10.1103/PhysRev.127.1892.

[27] M.J. Weber, R.W. Bierig, Paramagnetic resonance and relaxation of trivalent rare-earth ions in calcium fluoride. I. Resonance spectra and crystal fields, Phys. Rev. 134 (1964). doi:10.1103/PhysRev.134.A1492.

[28] M.M. Abraham, L.A. Boatner, J.O. Ramey, M. Rappaz, An EPR study of rare-earth impurities in single crystals of the zircon-structure orthophosphates $\mathrm{ScPO}_{4}, \mathrm{YPO}_{4}$, and $\mathrm{LuPO}_{4}$, J. Chem. Phys. 78 (1983) 3-10. doi:10.1063/1.444516.

[29] J.L. Boldú O, M.M. Abraham, L.A. Boatner, EPR characterization of $\mathrm{Er}^{3+}$ and $\mathrm{Yb}^{3+}$ in single crystals of synthetic perovskite $\left(\mathrm{CaTiO}_{3}\right)$, J. Chem. Phys. 86 (1987) 5267-5272. doi:10.1063/1.452772.

[30] H.R. Asatryan, J. Rosa, J.A. Mareš, EPR studies of $\mathrm{Er}^{3+}, \mathrm{Nd}^{3+}$ and $\mathrm{Ce}^{3+}$ in $\mathrm{YAlO}_{3}$ single crystals, Solid State Commun. 104 (1997) 5-9. doi:10.1016/S0038-1098(97)00258-5.

[31] S. Stoll, CW-EPR Spectral Simulations: Solid State, Methods Enzymol. 563 (2015) 121-142. doi:10.1016/bs.mie.2015.06.003.

[32] I.A. Irisova, A.A. Rodionov, D.A. Tayurskii, R. V. Yusupov, EPR studies of the mechanochemically $\mathrm{Er}^{3+}$-activated fluorite nanoparticles, J. Phys. Conf. Ser. 324 (2011) 1-7. doi:10.1088/1742-6596/324/1/012026.

[33] R.M. Rakhmatullin, I.N. Kurkin, V. V. Pavlov, V. V. Semashko, EPR, optical, and dielectric spectroscopy of Er-doped cerium dioxide nanoparticles, Phys. Status Solidi Basic Res. 251 (2014) 1545-1551. doi:10.1002/pssb.201451116.

[34] J. Kliava, EPR of Impurity Ions in Disordered Soilds, Phys. Stat. Sol. B. 134 (1986) 411-455. doi:10.1002/pssb.2221340202.

[35] D.L. Griscom, Electron spin resonance in glasses, J. Non. Cryst. Solids. 40 (1980) 211-272. doi:10.1016/0022-3093(80)90105-2.

[36] D.L. Griscom, Optical properties and structure of defects in silica glass, J. Ceram. Soc. Japan. Int. Ed. (1991).

[37] H. Yamada, K. Kojima, Upconversion fluorescence in $\mathrm{Er}^{3+}$-doped $\mathrm{Na}_{2} \mathrm{O}-\mathrm{GeO}_{2}$ glasses, J. Non. Cryst. Solids. 259 (1999) 57-62. doi:10.1016/S0022-3093(99)00495-0.

[38] G. Dantelle, M. Mortier, D. Vivien, EPR and optical studies of erbium-doped $\beta-\mathrm{PbF}_{2}$ singlecrystals and nanocrystals in transparent glass-ceramics, Phys. Chem. Chem. Phys. 9 (2007) 5591. doi:10.1039/b706735f.

[39] C. Lin, L. Calvez, Z. Li, S. Dai, H. Tao, H. Ma, X. Zhang, B. Moine, X. Zhao, Enhanced Up- 
Conversion Luminescence in $\mathrm{Er}^{3+}$-Doped $25 \mathrm{GeS}_{2} \cdot 35 \mathrm{Ga}_{2} \mathrm{~S}_{3} \cdot 40 \mathrm{CsCl}$ Chalcogenide GlassCeramics, J. Am. Ceram. Soc. 96 (2013) 816-819. doi:10.1111/jace.12102.

[40] W. Kaewwiset, K. Thamaphat, J. Kaewkhao, P. Limsuwan, ESR and spectral studies of $\mathrm{Er}^{3+}$ ions in soda-lime silicate glass, Phys. B Condens. Matter. 409 (2013) 24-29. doi:10.1016/j.physb.2012.10.004.

[41] V. Pukhkaya, Influence of $\mathrm{Yb}^{3+}$ and $\mathrm{Er}^{3+}$ ions environment on the evolution of its' luminescent properties in oxide glasses under ionizing irradiation, Ecole Polytechnique X, 2013.

[42] B. V. Padlyak, R. Lisiecki, W. Ryba-Romanowski, Spectroscopy of the Er-doped lithium tetraborate glasses, Opt. Mater. (Amst). 54 (2016) 126-133. doi:10.1016/j.optmat.2016.02.025.

[43] A. Antuzevics, U. Rogulis, A. Fedotovs, A.I. Popov, Crystalline phase detection in glass ceramics by EPR spectroscopy, Low Temp. Phys. 44 (2018) 449-454. doi:10.1063/1.5030462.

[44] A. Antuzevics, EPR in glass ceramics, (2019) 161-190. doi:10.1016/B978-0-12-8140246.00008-X.

[45] S. Brovelli, N. Chiodini, F. Meinardi, A. Monguzzi, A. Lauria, R. Lorenzi, B. Vodopivec, M.C. Mozzati, A. Paleari, Confined diffusion of erbium excitations in $\mathrm{SnO}_{2}$ nanoparticles embedded in silica: A time-resolved infrared luminescence study, Phys. Rev. B - Condens. Matter Mater. Phys. 79 (2009) 3-6. doi:10.1103/PhysRevB.79.153108.

[46] A. Antuzevics, G. Krieke, E. Pavlovska, U. Rogulis, $\mathrm{Eu}^{3+}$ ion distribution in oxyfluoride glass $\begin{array}{lllllll}\text { nanocomposites, } & \text { J. } & \text { Non. } & \text { Cryst. } & \text { Solids. } & 522 & \text { (2019) }\end{array} 119548$. doi:10.1016/j.jnoncrysol.2019.119548.

[47] H.A. Buckmaster, Y.H. Shing, A survey of the EPR spectra of $\mathrm{Gd}^{3+}$ in single crystals, Phys. Status Solidi. 12 (1972) 325-361. doi:10.1002/pssa.2210120202.

[48] K. Binnemans, Interpretation of europium(III) spectra, Coord. Chem. Rev. 295 (2015) 1-45. doi:10.1016/j.ccr.2015.02.015.

[49] G.K. Miner, T.P. Graham, G.T. Johnston, Effect of a Ce ${ }^{3+}$ Codopant on the $\mathrm{Gd}^{3+}$ EPR Spectrum of $\mathrm{SrF}_{2}$ at Room Temperature, J. Chem. Phys. 57 (1972) 1263-1270. doi:10.1063/1.1678385.

[50] E. Laredo, N. Suarez, A. Bello, M. Puma, Clustering of $\mathrm{Y}^{3+}$ in $\mathrm{BaF}_{2}$ using $\mathrm{Gd}^{3+}$ as paramagnetic probes, Solid State Ionics. 37 (1990) 103-113. doi:10.1016/0167-2738(90)90233-H.

[51] A.B. Arauzo, R. Alcala, P.J. Alonso, Pulsed EPR Spectroscopy of $\mathrm{Gd}^{3+}$ Centers in $\mathrm{Ca}_{1-\mathrm{x}} \mathrm{R}_{\mathrm{x}} \mathrm{F}_{2+\mathrm{x}}$ (R=La, Y) Mixed Crystals, Appl. Magn. Reson. 12 (1997) 375-387.

[52] U. Rogulis, Optical detection of paramagnetic centres: From crystals to glass-ceramics, Fiz. Nizk. Temp. 42 (2016) 689-693. doi:10.1063/1.4959009.

[53] J.M. Spaeth, H. Overhof, Point Defects in Semiconductors and Insulators, 2003. doi:10.1007/978-3-642-55615-9. 
Institute of Solid State Physics, University of Latvia as the Center of Excellence has received funding from the European Union's Horizon 2020 Framework Programme H2020-WIDESPREAD-01-2016-2017-TeamingPhase2 under grant agreement No. 739508 , project CAMART² 